\title{
Olfactory function in patients with olfactory groove meningioma
}

\author{
A Welge-Luessen, A Temmel, C Quint, B Moll, S Wolf, T Hummel
}

Department of

Otorhinolaryngology,

University Hospital,

Basel, Switzerland

A Welge-Luessen

Department of

Pharmacology,

University of

Erlangen-Nürnberg,

Krankenhausstrasse 9,

D-91054 Erlangen,

Germany

A Welge-Luessen

\section{Department of}

Otorhinolaryngology

S Wolf

Department of

Otorhinolaryngology,

University of Vienna,

Vienna, Austria

A Temmel

C Quint

Department of Otorhinolaryngology,

University of Mainz,

Mainz, Germany

B Moll

Department of Otorhinolaryngology, University of Dresden

Medical School,

Dresden, Germany

T Hummel

Correspondance to: $\mathrm{Dr} A$ Welge-Luessen

awl@pharmako.pharmakologie. uni-erlangen.de

Received 16 May 2000 and in revised form

4 August 2000

Accepted 21 September

2000

\begin{abstract}
Objectives-Olfactory meningiomas are rare benign tumours and represent about $12 \%$ of all basal meningiomas. Anosmia is thought to be among the first symptoms, even though patients often present with headaches or visual problems. However, so far no detailed physophysical tests of olfactory function have been performed in a large number of those patients.

Methods-Twelve patients (five men, seven women; mean age 52 years) with olfactory meningiomas were examined. In all patients extensive preoperative and postoperative lateralised olfactory testing was performed using the "Sniffin' Sticks" test battery, a psychometric testing tool. In eight cases the meningioma was lateralised (five left, three right), in four patients a bilateral meningioma was found. In addition to a detailed ear, nose, and throat examination MRI was performed in all patients.

Results-In preoperative testing six patients were found to be anosmic on the side of the tumour, two were hyposmic. Four patients were normosmic. Postoperative investigations showed lateralised anosmia in four patients on the operated side, three were normosmic on the contralateral side and one hyposmic. The remaining eight patients were completely anosmic postoperatively.

Conclusions-(1) Contrary to expectations, olfactory testing seems to be of little help in detecting olfactory meningiomas. (2) The likelihood of normal postoperative olfactory function contralateral to the tumour was high when the tumour was less than $3 \mathrm{~cm}$ in diameter and preoperative normosmia had been established. (3) Preservation of olfactory function ipsilateral to the tumour seems to be extremely difficult, irrespective of tumour size or surgical approach.

(F Neurol Neurosurg Psychiatry 2001;70:218-221)
\end{abstract}

Keywords: olfactory function; olfactory groove meningioma

Olfactory groove meningiomas are rare, benign intracranial tumours. In histological series they represent $8 \%-18 \%$ of all intracranial meningiomas in histological series. ${ }^{1-3}$ Meningiomas are said to arise from arachnoid cap cells, which are specialised cells in arachnoid granulations. ${ }^{45}$ They account for about $20 \%$ of all intracranial tumours and grow slowly and usually remain clinically undetectable during the early stages. ${ }^{6}$ Therefore they are often of considerable size when patients present to the neurosurgeon. ${ }^{78}$ Even though unilateral or bilateral olfactory dysfunction is supposed to be the earliest symptom only a few patients are aware of olfactory loss. Most patients present with headache, visual disturbances, loss of intellectual functions, or memory disturbances. ${ }^{89}$ However, investigations of olfactory function in a larger group of patients are lacking so far. We therefore present a series of 12 patients with olfactory groove meningioma who underwent extensive testing preoperatively and postoperatively using a standardised test battery. Moreover, we were interested in a possible correlation between olfactory function and size of the tumour.

\section{Methods}

We examined 12 patients, five men and seven women, with a mean age of 51 years (range 21-71) who presented to the hospitals between 1998 and 2000. Tumour diagnosis was performed in all patients by means of MRI examination. All patients were operated on via frontal or bifrontal craniectomy in the neurosurgery departments of the hospitals.

In five patients the tumour was localised on the left side, in four on the right, and in four patients the tumour was found bilaterally. Tumour size ranged from $2 \mathrm{~cm}$ to $5.5 \mathrm{~cm}$ in diameter. Preoperatively all but one patient received both a complete ear, nose, and throat examination (including nasal endoscopy to exclude mechanical obstruction of the olfactory cleft) and lateralised testing of olfactory function. Postoperative examination was performed after 2 to 12 weeks; it included nasal endoscopy and lateralised olfactory function tests.

The psychophysical testing of olfactory function was performed using the "Sniffin' Sticks" test battery. ${ }^{10-11}$ It consists of tests for odour threshold, discrimination, and identification. Odorants are presented using plastic pens, similar to felt tip marking pens, that are either filled with undiluted or a liquid solution of the odorant. The pens are presented in front of either nostril or in front of both nostrils.

\section{ODOUR THRESHOLD}

A single staircase method employing a forced choice paradigm is used. The pens contain dilutions of $n$-butanol in $50 \%$ dilution steps (highest concentration of $n$-butanol $4 \%$ ). In addition, two blanks are presented. The patient has to decide which pen smells different. Identifying the odorant correctly in two successive trials triggers a reversal of the staircase. The 

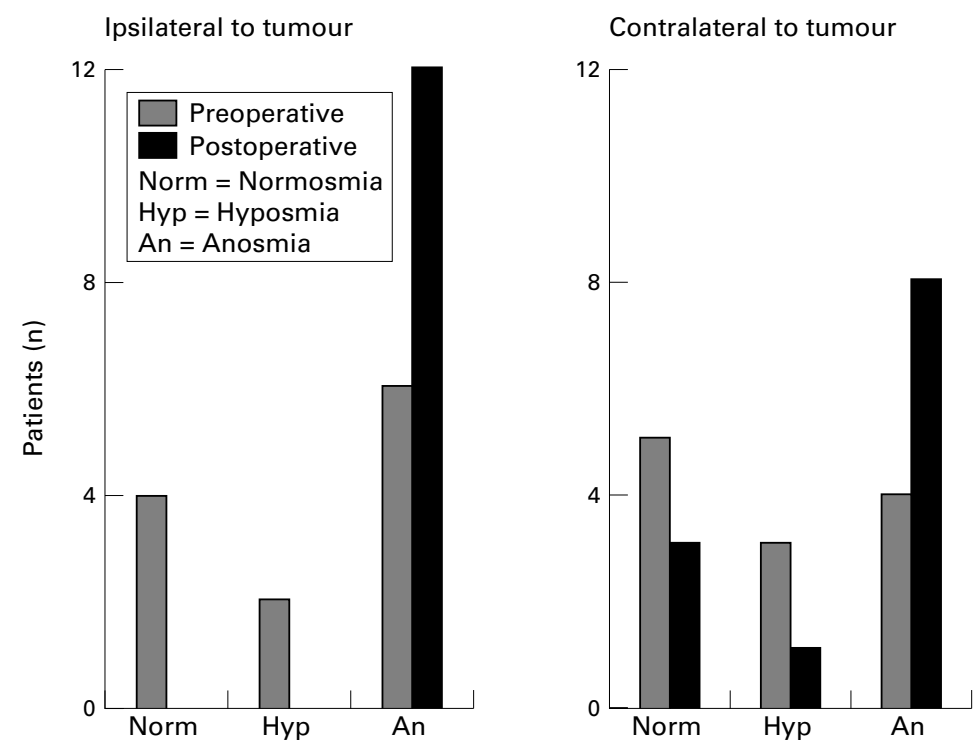

Figure 1 Olfactory function in patients with meningioma before and after neurosurgical resection of the tumour. Preoperatively one third of the patients had normal olfactory function on both sides. Ipsilateral to the tumour, it was impossible to preserve olfactory function.

mean of the last four of seven staircase reversal points is used as the threshold estimate. The maximum score is 16 , the lowest is 0 .

ODOUR DISCRIMINATION

The patient sniffs three pens, two containing the same odorant and one containing a different one. In this triple forced choice paradigm patients are asked to identify the pen that smells different. The scores range from 0 to 16 . Throughout both threshold and discrimination tests the patient is blindfolded.

ODOUR IDENTIFICATION

Sixteen pens with common odours are presented and have to be identified from a list of four items each. Scores range from 0 to 16 .

\section{SCORING}

Scores from the three subtests (threshold, discrimination, identification) were added to receive the TDI score ranging from from 0 to 48. A TDI score smaller than 16 is defined as functional anosmia, a TDI score smaller than 31 as hyposmia. $^{12}$

Preoperative olfactory function in relation to the side of tumour lateralisation

\begin{tabular}{|c|c|c|c|c|c|c|c|}
\hline \multirow{3}{*}{$\begin{array}{l}\text { Patient } \\
\text { No }\end{array}$} & \multirow{3}{*}{$\begin{array}{l}\text { Lateralisation } \\
\text { of tumour }\end{array}$} & \multicolumn{6}{|c|}{ Olfactory function } \\
\hline & & \multicolumn{3}{|c|}{ Ipsilateral } & \multicolumn{3}{|c|}{ Contralateral } \\
\hline & & $A$ & $H$ & $N$ & $A$ & $H$ & $N$ \\
\hline 1 & $\mathrm{~L}$ & & & $x$ & & & $x$ \\
\hline 2 & $\mathrm{~L}$ & & & $x$ & & & $\mathrm{x}$ \\
\hline 3 & $\mathrm{R}$ & & & $x$ & & & $x$ \\
\hline 4 & $\mathrm{R}$ & & & $x$ & & & $x$ \\
\hline 5 & $\mathrm{~L}$ & $\mathrm{x}$ & & & & & $\mathrm{x}$ \\
\hline 6 & $\mathrm{~L}$ & & $x$ & & & $x$ & \\
\hline 7 & $\mathrm{~L}$ & & $x$ & & & $x$ & \\
\hline 8 & $\mathrm{Bi}$ & $\mathrm{x}$ & & & $\mathrm{x}$ & & \\
\hline 9 & $\mathrm{Bi}$ & $\mathrm{x}$ & & & $\mathrm{x}$ & & \\
\hline 10 & $\mathrm{Bi}$ & $\mathrm{x}$ & & & $\mathrm{x}$ & & \\
\hline 11 & $\mathrm{Bi}$ & $x$ & & & $x$ & & \\
\hline 12 & $\mathrm{R}$ & $x$ & & & & $x$ & \\
\hline
\end{tabular}

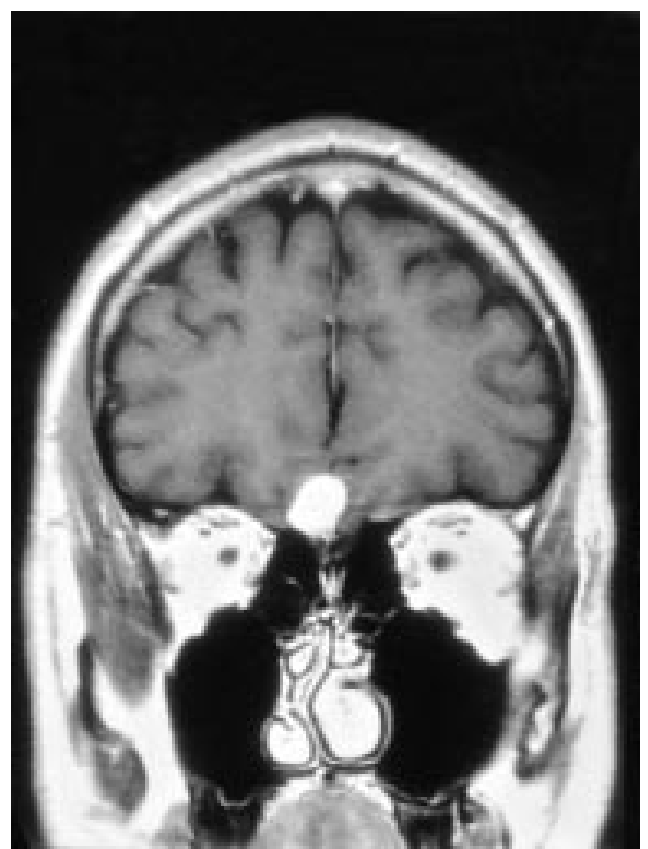

Figure 2 MRI of a patient (3) showing a predominantly right sided olfactory meningioma.

In two patients chemosensory evoked potentials were recorded postoperatively in response to lateralised stimulation. Using an olfactometer (OM 2b, Burghart, Wedel, Germany), a continuous airstream with controlled temperature $\left(36.5^{\circ} \mathrm{C}\right)$ and constant humidity $(80 \%)$ was directed into the nasal cavity. For olfactory stimulation pulses of $\mathrm{H}_{2} \mathrm{~S}$ stimuli (2-6 ppm) were embedded in the constantly flowing airstream, the trigeminal stimulant $\mathrm{CO}_{2}(66 \%$ $\mathrm{v} / \mathrm{v}$ ) was used as a control (stimulus duration $200 \mathrm{~ms}$, interstimulus interval $40 \mathrm{~s}$ ). Twenty stimulus linked records were averaged to obtain chemosensory evoked potentials recorded from three midline positions $(\mathrm{Fz}, \mathrm{Cz}$, $\mathrm{Pz}){ }^{13}$

\section{Results}

Complete removal of the meningioma was achieved in all cases. Postoperative outcome was succesful in 11 patients; one patient died on the second postoperative day due to untreatable increase of intracranial pressure. Eight patients had unilateral tumours and four had a bilateral tumour.

According to the psychophysical tests of olfactory function preoperatively four patients were found to be normosmic on both sides (fig 1). Two patients were hyposmic on both sides (TDI scores right/left 26/22; 25/22). Six patients had anosmia ipsilaterally to the tumour, four of them were completely anosmic, two had contralateral hyposmia or normosmia. In two patients it was possible to keep the olfactory tract at the side of the tumour anatomically intact during the operation. Despite this, both patients were postoperatively anosmic on this side. When following up one of these patients for a period of 24 months anosmia ipsilateral to the tumour was still present. The four patients with bilateral anosmia had a large bilateral tumour, whereas all others had a lateralised tumour (table). 

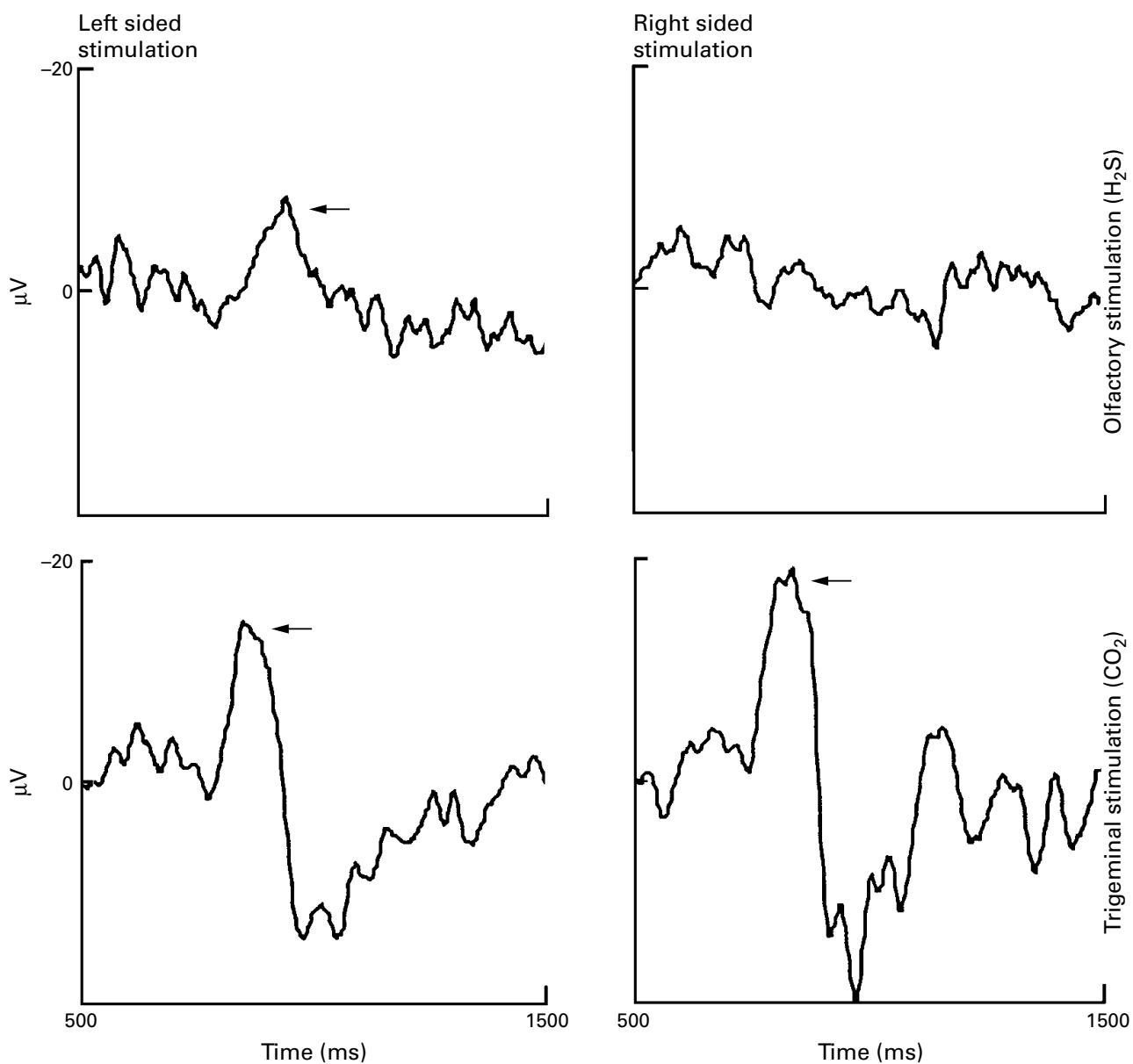

Figure 3 Postoperatively on the left side olfactory and chemosomatosensory evoked potentials are seen whereas on the side of the tumour (right side) only chemosomatosensory evoked potentials are seen.

The two patients in whom chemosensory evoked potentials were recorded had a postoperative normosmia on the contralateral side, and anosmia on the side of the tumour, respectively. One patient is described in more detail:

CASE 1

A 41 year old woman had recurrent vertigo. No olfactory loss, headache, mental disorder, or visual symptoms were reported on questioning. Examinations for vertigo included MRI; it disclosed a right sided frontal tumour suspected to be an olfactory meningioma (fig 2). The vertigo was classified later as benign positional vertigo. Preoperative olfactory testing indicated bilateral normosmia; postoperatively she had contralateral normosmia and ipsilateral anosmia when tested 6 weeks postoperatively. This was despite the surgical preservation of both olfactory bulbs and tracts. Preoperative chemosensory evoked potentials showed responses to left and right sided stimulation with both olfactory and trigeminal stimuli. Postoperatively olfactory responses were not present on the operated side (fig 3).

\section{Discussion}

About $8 \%-18 \%$ of all intracranial meningiomas are olfactory meningiomas. ${ }^{1}$ Growth is usually slow. Due to their localisation they often reach a very large size $(>4 \mathrm{~cm})^{14}$ before the diagnosis is made. ${ }^{815}$ Although anosmia is thought to be an early symptom, surprisingly few patients complain of olfactory dysfunction. This may be due to the fact that (1) the decline in olfactory function is gradual, similar to what is seen in elderly patients, ${ }^{16}$ and that (2) in most of the patients only one side of the nose is affected such that olfactory function is maintained by the contralateral side. ${ }^{17}{ }^{18}$ Thus, lateralised anosmia is extremely difficult to detect during routine clinical examinations in patients in whom it is the only neurological symptom before the tumour becomes large enough to affect other structures. ${ }^{8}$ In our series we had four patients who were bilaterally normosmic; one patient was normosmic on the side contralateral to the meningioma. In all these patients presence of an olfactory meningioma had not been suspected. The diagnosis was made on the basis of MRI which had been performed by coincidence and not as a consequence of olfactory evaluation.

To detect an olfactory meningioma, lateralised testing of olfactory function seems to be necessary. From the 12 patients investigated three had asymmetric test results, which should lead to further investigations including MRI or CT -given that there is no intranasal pathology which might explain lateralised dysfunction. Specifically, based on data provided by Klimek et $a l^{17}$ a clinically significant difference in olfac- 
tory function can be assumed if the difference in TDI score between the left and right side is 6 or more-which was the case in all three patients with lateralised dysfunction.

Size of the meningioma seems to be a major factor in post-operative olfactory function contralateral to the side where the meningioma probably originated. The surgical approach also has to be taken into consideration. Using a pterional approach in 11 cases of olfactory meningiomas, Hassler and Zentner ${ }^{19}$ were able to preserve the contralateral olfactory tract with good function in two cases. Unfortunately they did not report olfactory function ipsilateral to the tumour. In extension of the previous findings by Hassler and Zentner, the present work also indicated that ipsilateral anosmia was present even when it was possible to anatomically preserve olfactory bulbs and tracts ipsilateral to the tumour.

Explanations for olfactory loss may relate to diminished blood supply after surgery, ${ }^{20}$ or functional lesions due to intrasurgical movement of the olfactory bulbs and tracts. In addition, size of the tumour certainly plays a part in postoperative mortality. Although this appears to be a complex, multifactorial issue both size of the tumour and duration of the operation are key factors in postoperative outcome. ${ }^{21}$ In our series one patient died within 24 hours postoperatively, directly related to the operation; here, the tumour was very large $(5 \times 5 \times 4.5 \mathrm{~cm})$ and surgery lasted for about 8 hours.

On the side contralateral to the tumour preservation of olfactory function was possible in three patients, in whom the tumour was smaller than $3 \mathrm{~cm}$ in diameter and preoperative normosmia had been established on both sides. Postoperatively, these patients were tested normosmic, which definitively will contribute to their quality of life. ${ }^{22}$

Interestingly, our findings also indicated that even bilateral normosmia does not rule out the presence of a meningioma of less than $3 \mathrm{~cm}$ diameter in size. Although it can be assumed that the tumour is too small to have an impact on olfactory function, this also suggests that it is extremely difficult to detect the presence of small olfactory meningiomas on the basis of olfactory function tests or clinical symptoms related to olfactory loss.

In conclusion, the present data indicated the following: (1) contrary to expectations, olfactory testing seems to be of little help in detecting olfactory meningiomas. This may be the case even when olfactory function is assessed separately for each nostril using relatively complex procedures. Specifically, olfactory loss was not present for smaller olfactory meningiomas. In addition, even with larger meningiomas patients did not report decreased olfactory function which was consistent with normal olfactory function contralateral to the tumour. (2) The likelihood of normal postoperative olfactory function contralateral to the tumour was high when the tumour was less than $3 \mathrm{~cm}$ in diameter and preoperative normosmia had been established. (3) Preservation of olfactory function ipsilateral to the tumour seems to be extremely difficult, irrespective of tumour size or surgical approach.

1 Mc Dermott MW, Wilson CB. Meningiomas . In: Youmans, JR, ed. Neurological surgery. 4th ed. Philadelphia: Saunders, 1996.

2 Chan RC, Thompson GB. Morbidity, mortality and quality of life following surgery for intracranial meningiomas: a
retrospective study of 257 cases. $\mathcal{F}$ Neurosurg 1984;60:5260

3 Cushing H, Eisenhart L. Meningiomas: their classification, regional behavior, life history and surgical end results. Springfield, IL: Charles C Thomas, 1938.

4 Kepes JJ. Meningiomas: biology, pathology and differential diagnosis. New York: Masson, 1982.

5 O'Rahilly R, Miller F. The meninges in human development. F Neuropathol Exp Neurol 1986;45:588-608.

6 Rachlin JR, Rosenblum ML. Etiology and biology of meningiomas. In: Al-Mefty O, ed. Meningiomas. New York: Raven, 1991:27-32.

7 Babu R, Barton A, Kasoff SS. Resection of olfactory groove meningiomas: technical note revisited. Surg Neurol 1995; 44:567-72.

8 Bakay L. Olfactory meningiomas. The missed diagnosis. $7 A M A 1984 ; 251: 53-5$

Tsikoudas A, Martin-Hirsch DP. Olfactory groove meningiomas. Clin Oltolaryngol 1999;24:507-9.

10 Kobal G, Hummel T, Sekinger B, et al. Sniffin'Sticks: screening of olfactory performance. Rhinology 1996;34: 222-6.

11 Hummel T, Sekinger B, Wolf SR, et al. 'Sniffin'Sticks': olfactory performance assessed by the combined testing of odor identification, odor discrimination, and olfactory thresholds. Chem Senses 1997;22:39-52.

12 Kobal G, Klimek L, Wolfensberger M, et al. Multi-center investigation of 1036 subjects using a standardized method for the assessment of olfactory function combining tests of odor identification, odor discrimination, and olfactory thresholds. Eur Arch Otorhinolaryngol 2000;257:205-11.

13 Kobal G, Hummel T. Olfactory evoked potentials in humans. In: Getchell TV, Doty RL, Bartoshuk LM, et al, eds. Smell and taste in health and disease. New York: Raven, 1991:255-75

14 Ojemann RG. Olfactory groove meningiomas. In: Al-Mefty O, ed. Meningiomas. New York: Raven, 1991:383-93.

15 Schmitt HE, Ahyai A, Spoerri O. Die Verantwortung des HNO-Arztes bei der Erkennung des Olfaktoriusmeningioms. HNO 1982;30:56-9.

16 Wysocki CJ, Gilbert AN. National Geographic smell survey: effects of age are heterogenous. In: Murphy C, Cain WS, effects of age are heterogenous. In: Murphy C, Cain
Hegsted DM, eds. Ann NY Acad Sci 1989;561:12-28.

17 Klimek L, Hummel T, Moll B, et al. Lateralized and bilateral olfactory function in patients with chronic sinusitis compared to healthy controls. Laryngoscope 1998;108:11114.

18 Betchen SA, Doty RL. Bilateral detection thresholds in dextrals and sinistrals reflect the more sensitive side of the nose, which is not lateralized. Chem Senses 1998,23:453-7. ment of olfactory groove meningiomas. Neurosurgery 1989 ; 6:942-5.

20 Kumoi T, Iritani H, Nishimura Y, et al. Animal model for ischemic facial nerve paralysis with selective vascular embolization. Ann Otol Rhinol Laryngo 1992;101:423-9.

21 Black PMcL. Meningiomas. Neurosurgery 1993;32:643-57.

22 Van Toller S. Assessing the impact of anosmia: review of a questionnaire's findings. Chem Senses 1999;24:705-12. 